See discussions, stats, and author profiles for this publication at: https://www.researchgate.net/publication/322878564

\title{
Biofidelic Conductive Synthetic Skin Composites
}

Conference Paper · November 2017

DOI: $10.12783 /$ asc2017/15197

CITATIONS

3 authors, including:

Arnab Chanda

5) University of Pittsburgh

24 PUBLICATIONS 152 CITATIONS

SEE PROFILE

Some of the authors of this publication are also working on these related projects:

Multi-Scale modeling of Carbon Nanotubes View project

OneSoles: The Highly Customizable Insoles View project
READS

24

V. U. Unnikrishnan

University of Alabama

55 PUBLICATIONS 295 CITATIONS

SEE PROFILE 


\title{
Biofidelic Conductive Synthetic Skin Composites
}

ARNAB CHANDA ${ }^{1}$, VINU UNNIKRISHNAN ${ }^{2}$, and KIM LACKEY³

\begin{abstract}
Skin is the first point of contact of the human body with the outer environment, and influences the biomechanics of different organ systems in normal and diseased states. Wearable electronics such as fitness tracking equipment, motion sensing devices, and advanced wearables in prosthetics and orthotics are often used to quantify the interaction of the body with the environment during different physical activities, and improve health. These wearable equipment can be bulky and a source of discomfort to the human skin with prolonged wear. To date, very few flexible polymers have been developed which can conduct electricity and be used in wearable devices. In the current work, a novel conductive synthetic skin composite system was developed, which would be indispensable for integration into wearable technologies, and also allow the biomechanical testing of the human skin for different engineering and medical applications. The mechanical behavior of this polymer can be tuned to mimic the human skin from different locations of the body with varying stiffnesses, with a phenomenal degree of accuracy. The composite system is composed of short carbon fibers dispersed in a multi part silicone based matrix material. The volume fraction of the fibers were varied to control the mechanical and electrical properties of the composite. Uniaxial tensile tests were conducted to generate stress versus strain responses of the synthetic skin composites at different fiber volume fractions, and electrical measurements were recorded at different strains. Microscopy was used to understand composite fiber orientations in unstretched and stretched states, and its effects on the electrical conductivity of the material. Additionally, non-linear material characterization models were developed to characterize the composite variants. To the best of our knowledge, such an accurate synthetic skin composite system with tailorable electrical properties has not been developed; making this state of the art in bio mimicking and functionalization of the human skin.
\end{abstract}

\section{INTRODUCTION}

The skin is the first point of contact of the human body with external loads and environmental interactions, and protects it from damage. As a material, skin is a 1-4 mm

1 Graduate Student, Department of Aerospace Engineering and Mechanics, University of Alabama, Tuscaloosa, 35487, USA

2 Assistant Professor, Department of Aerospace Engineering and Mechanics, University of Alabama, Tuscaloosa, 35487, USA

${ }^{3}$ Assistant Professor, Department of Biological Sciences, University of Alabama, Tuscaloosa, 35487, USA 
thick composite system with three layers namely the epidermis (outermost layer), the dermis (middle layer) and hypodermis (inner most layer which transitions into the muscles) [1] (Figure 1). To date, a plethora of material models have been developed to simulate the skin for tissue engineering applications [2], surgical suture simulations [3], and to study its resistance to injuries [4, 5] and ballistic impact loads [6-9]. However, so far, the realistic hyperelastic material behavior of the human skin has never been simulated, which is indispensable for biomechanical testing applications such as estimating the load response of wearable technologies, cosmetic implants and biomechanical study of skin mechanics. Recently, the authors [10] developed an isotropic biofidelic skin simulant material which can accurately simulate the mechanical response of skin with different stiffnesses from different locations of the body.

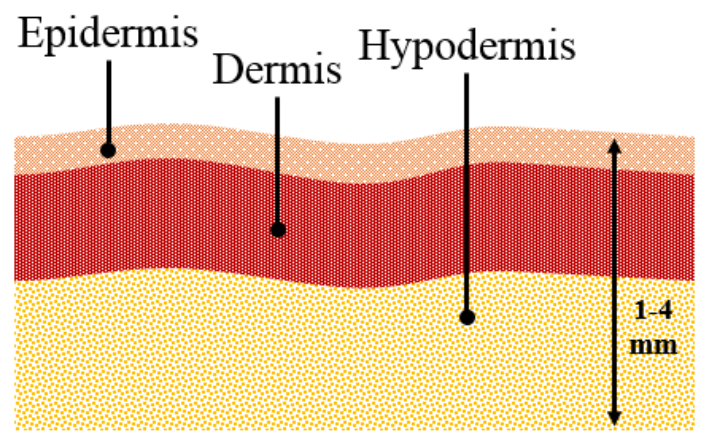

Figure 1. Three layers of human skin composite

Soft conductive polymers have been developed in the past with carbon and metal based filler materials to advance research and testing of wearable technologies and for acquisition of biomechanical information from the human body [11]. However, none of these conductive materials are able to simulate human tissue behavior. In the current work, a conductive synthetic skin composite is developed, which can precisely simulate the mechanical properties of the human skin. The following sections will discuss the material system in detail, the mechanical testing framework, and biomechanical characterization of the novel conductive synthetic skin composites.

\section{MATERIALS AND METHODS}

\section{FABRICATION AND MECHANICAL TESTING}

To develop skin like conductive polymers, two-part silicones, with Shore (Durometer) hardness of 30A and 00-10 respectively procured from Smooth-On Inc. and Polytek Inc. was used [10]. Over 30 coupons of $5 \mathrm{~cm}$ length, $1 \mathrm{~cm}$ width and $3 \mathrm{~mm}$ depth were fabricated for mechanical testing [10, 12, 13] (Figure 2). The synthetic skin composition used for the matrix material throughout the study was $45 \%$ wt. Shore $30 \mathrm{~A}$ (part A-hardener), 45\% wt. Shore 30A (part B-cross linker), 5\% wt. Shore 00-10 (part A-hardener) and 5\% wt. Shore 00-10 (part B-cross linker). Short carbon fibers chopped in different lengths $(0.5-6 \mathrm{~mm})$ and mixed in different weights fractions (FWF's) with the matrix material were used to generate the test coupons.

A microscope (Serial No. 29AX E250223 from Motic Inc.) was used to capture images of the test coupons before mechanical testing and a uniaxial test was conducted 
(on a MTS universal testing machine) to study the stress-stretch behavior of the test specimens. A well-established protocol was followed while testing the test coupons [10, $12,13]$. A constant strain rate of $0.4 \mathrm{~s}^{-1}$ and specimen size of $35 \mathrm{~mm} \times 10 \mathrm{~mm} \times 3 \mathrm{~mm}$ (after clamping) was selected for all the uniaxial tests based on literature $[4,5,14,15]$. A very small initial load was applied on each test specimen to remove any slack in the specimen before testing. For each of the tests, the true stress $\left(\sigma_{\text {eng }}\right)$ versus stretch $(\lambda)$ was plotted.

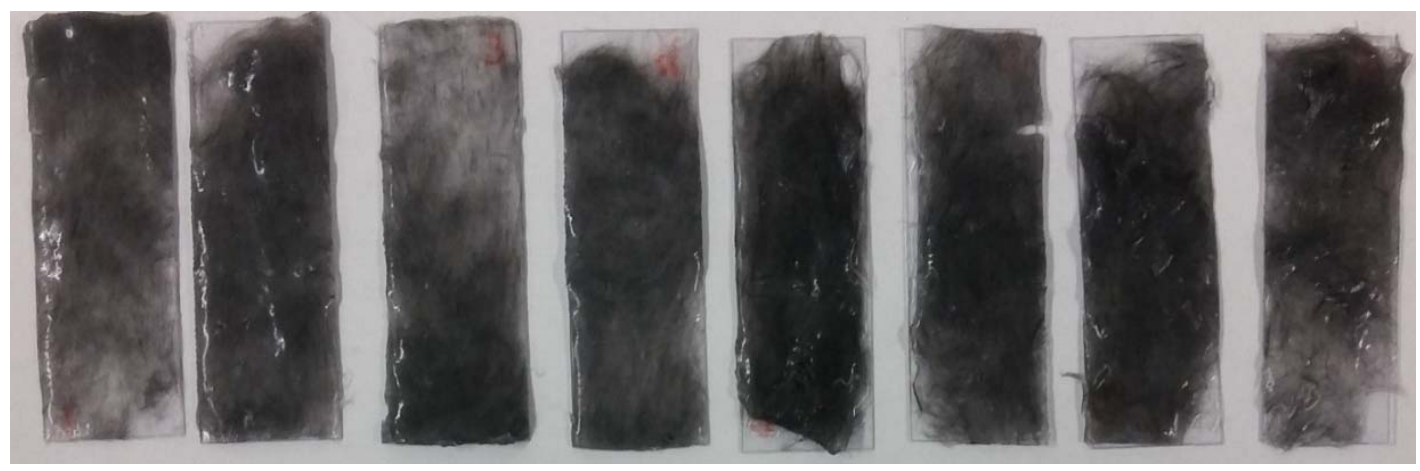

Figure 2. Conductive synthetic skin samples

\section{MECHANICAL AND ELECTRICAL TESTS AT DIFFERENT STRAINS}

The test coupons were stretched to $100 \%$ and $200 \%$ elongations and the respective electrical resistances were recorded at $1 \mathrm{~cm}$ and $5 \mathrm{~cm}$ spacing. Two MANNIX digital multimeters (Sr. no. DMM51FSG) were used which can measure resistances in the range of $200 \Omega-200 \mathrm{M} \Omega$. The resistance changes due to varying FWF's were estimated for unstretched coupons, and at 100\% and 200\% elongations. Also, for different elongations, the FWF values which would result in a low resistance value $(<1000 \Omega)$ were identified to understand material configurations for a highly flexible and consistently conducting synthetic skin composition. Additionally, microscopy was used to study fiber alignments in the composites at different strains.

\section{NON-LINEAR MATERIAL MODELING}

Soft tissues, polymers and rubbers exhibit a non-linear stress versus strain response which can be characterized using hyperelastic constitutive material models such as Fung, Mooney-Rivlin, Yeoh, Veronda-Westmann, and Humphrey [10, 12, 13, 16-23]. Hyperelastic curve fit models are based on the definition of the strain-energy function (denoted as $\Psi$ ), which depends on the type of material [24, 25]. A hyperelastic model is dependent on either the principal stretches $\left(\lambda_{1}, \lambda_{2}\right.$ and $\left.\lambda_{3}\right)$ or the Cauchy-Green tensor invariants $\left(I_{1}, I_{2}\right.$ and $I_{3}$, which are also functions of the principal stretches given by $I_{1}=\sum_{i=1}^{3} \lambda_{i}^{2}, I_{2}=\sum_{i, j=1}^{3} \lambda_{i}^{2} \lambda_{j}^{2}$, and $\left.I_{3}=\prod_{i=1}^{3} \lambda_{i}^{2}\right)$ [16]. Hyperelastic strain energy functions corresponding to the, Yeoh and Humphrey models are given by equations 1 and 2 which were used in the current work to curve fit the stress versus stretch relations of the composite specimens tested uniaxially. 


$$
\begin{gathered}
\sigma_{\text {Yeoh }}=2\left(\lambda^{2}-\frac{1}{\lambda}\right)\left(c_{1}+2 c_{2}\left(I_{1}-3\right)+3 c_{3}\left(I_{1}-3\right)^{2}\right) \\
\sigma_{\text {Humphrey }}=2\left(\lambda^{2}-\frac{1}{\lambda}\right) c_{1} c_{2} e^{c_{2}\left(I_{1}-3\right)}
\end{gathered}
$$

To have a high accuracy for the hyperelastic curve fits, an $\mathbf{R}^{\mathbf{2}}$ correlation value was estimated and only the plots which yielded an $\mathbf{R}^{\mathbf{2}}>0.96$ were selected.

\section{RESULTS AND DISCUSSION}

The fiber lengths and FWF were varied to understand the fiber requirements for a consistent electrical conduction through the synthetic skin material. The resistance value was observed to decrease with increasing fiber length. However, beyond a fiber length of approximately $5 \pm 0.5 \mathrm{~mm}$, the resistance value did not decrease further and was recorded to be consistently in the range of 13536-13578 $\Omega$ (see Figure 3). Thereby, $5 \pm 0.5 \mathrm{~mm}$ fiber length was considered as the optimum fiber length for the study.

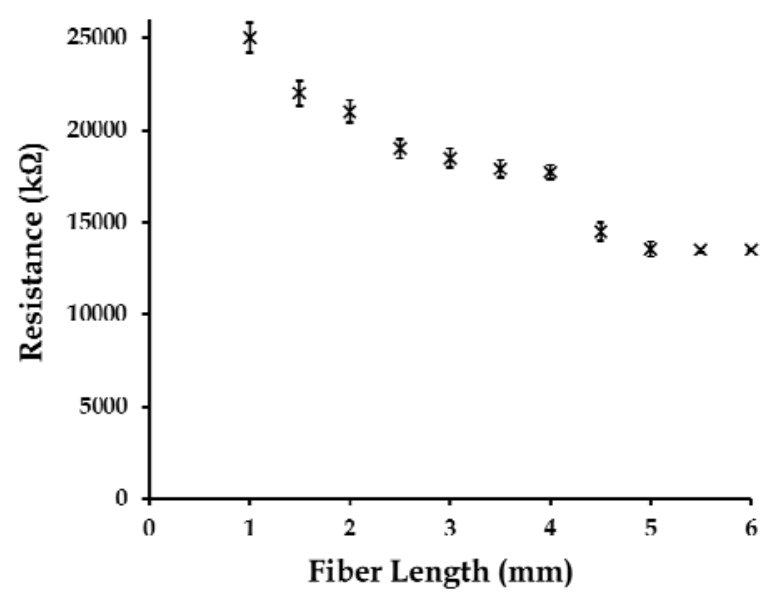

Figure 3: Resistances recorded at a $1 \mathrm{~cm}$ spacing for test coupons with $\mathrm{FWF}=0.15$ and different fiber lengths

Multiple test coupons (30) were generated with different FWF's and electrical measurements were conducted in an unstretched state. For FWF $>0.3$, a resistance of less than $1000 \Omega$ was measured. Figure 4 presents the summary of resistances recorded for different FWF's at a spacing of $1 \mathrm{~cm}$ and $5 \mathrm{~cm}$ respectively. 


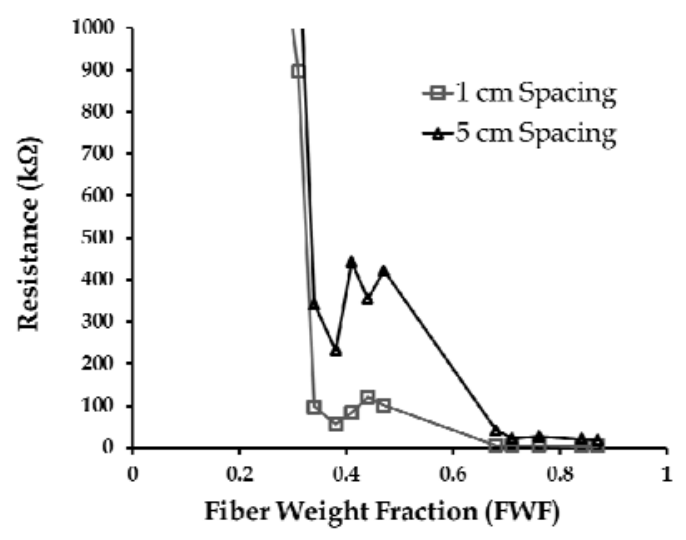

Figure 4: FWF versus resistances recorded at $1 \mathrm{~cm}$ and $5 \mathrm{~cm}$ spacing for test coupons in unstretched state

The test coupons were subjected to $100 \%$ and $200 \%$ elongations and the resistances were measured at $1 \mathrm{~cm}$ spacing. An increase was observed with the resistance values due to elongation. Figure 5 captures the resistance versus FWF for the elongations. A low resistance $<1000 \Omega$ was estimated for the $100 \%$ and $200 \%$ elongation cases for $\mathrm{FWF}>0.65$ and $\mathrm{FWF}>0.8$ respectively.

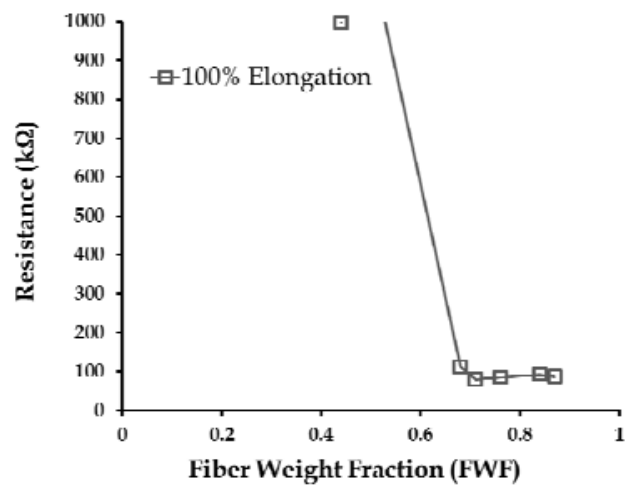

(A)

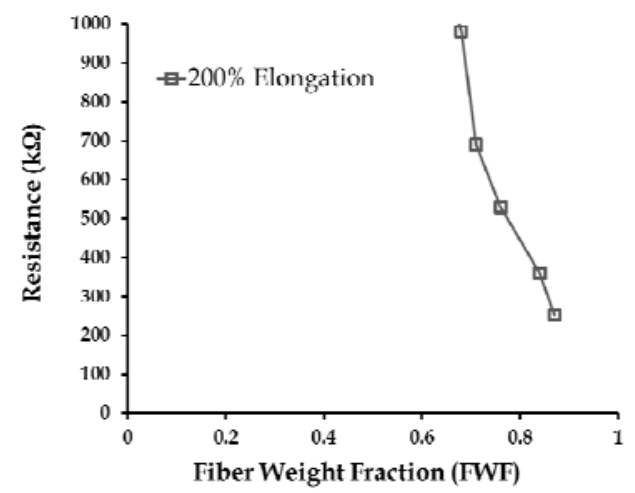

(B)

Figure 5: FWF versus resistances recorded at $1 \mathrm{~cm}$ spacing for: A) $100 \%$ elongation and B) $200 \%$ elongation

It can be concluded from Figures 4 and 5 that the conductivity of the novel conductive synthetic skin composite decreases with stretching. Therefore, for applications which require minimum stretching, a small FWF will suffice. However, for high stretch applications, a higher FWF is required to allow for unobstructed electrical conduction.

The change in fiber alignment due to elongation was observed under a microscope. Figure 6A captures the fiber alignment of one of the test coupons with FWF of 0.47 in unstretched state. Figure 6B and 6C shows the curling of fibers due to $100 \%$ and $200 \%$ elongations respectively captured after relaxation of the test specimen. It was concluded from the observations that strains lead to permanent curling of short carbon fibers within the matrix, which may result in significant residual stresses within the composite at high strains. The electrical properties were observed to change during and after stretching. For the specimen shown in Figure 6, the resistances measured at $1 \mathrm{~cm}$ spacing were 
recorded as $101 \Omega, 422 \Omega$ and $1341 \Omega$ for the unstretched state, $100 \%$ elongation and $200 \%$ elongation respectively. However, after multiple repeatability tests, these average values were found to be $394 \Omega, 513 \Omega$ and $1477 \Omega$ for the unstretched state, $100 \%$ elongation and $200 \%$ elongation respectively.

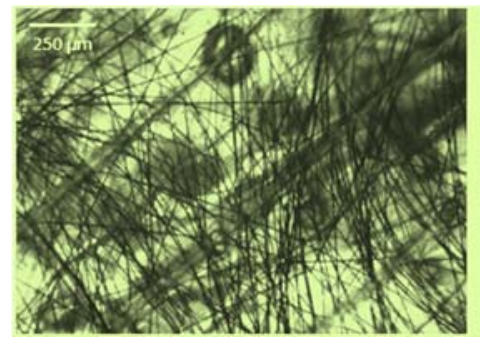

(A)

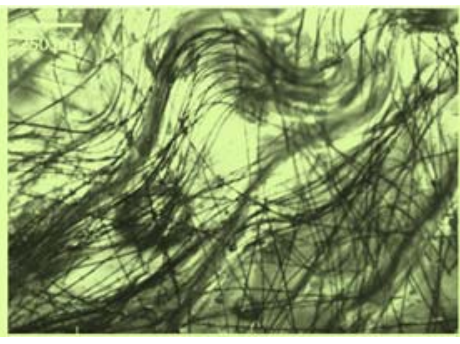

(B)

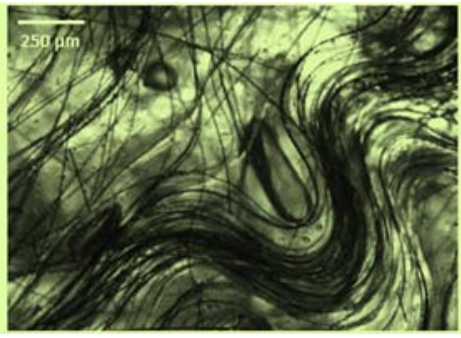

(C)

Figure 6: Microscopy images of test coupon with $\mathrm{FWF}=0.47$ in A) Unstretched state, B) $100 \%$ elongation and B) $200 \%$ elongation, showing fiber curling

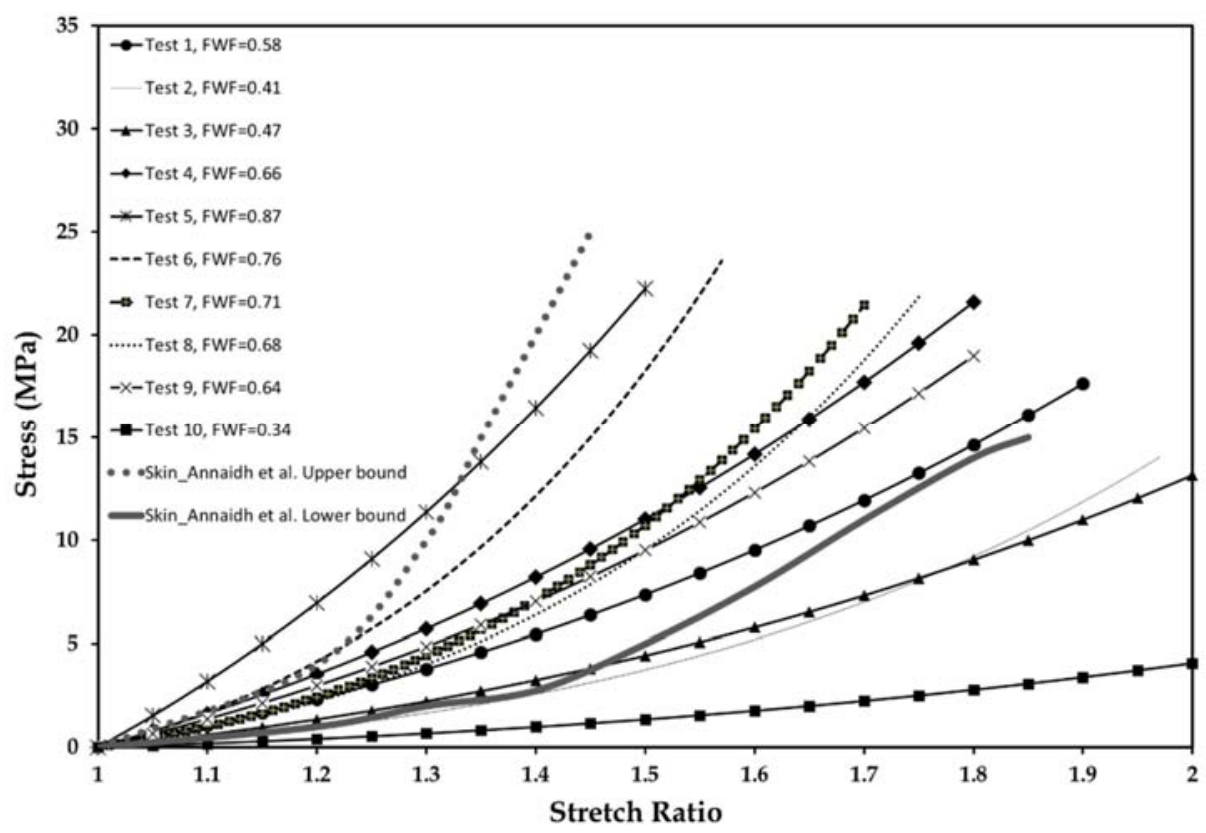

Figure 7: Stress versus stretch behavior of conductive synthetic skin composites with different FWF's, within the bounds of literature based excised skin tissue properties

\section{COMPOSITE MECHANICAL PROPERTY AT DIFFERENT FIBER WEIGHT FRACTIONS}

Test specimens were fabricated with the same matrix material and varying FWF's. Based on the uniaxial mechanical tests, the stress versus stretch responses of 10 composite compositions with different FWF's are presented in Figure 7. Figure 7 also shows the literature plots on mechanical tests on excised human skin (upper and lower bounds) $[4,5,14,15]$.

\section{NON-LINEAR MATERIAL CHARACTERIZATION}


The mechanical tests in Figure 7 were curve fitted using the Yeoh, and Humphrey hyperelastic material models. The various curve-fit parameters (c1, c2 and c3) for the respective material models are summarized in Table 1.

TABLE I. HYPERELASTIC CURVE FIT PARAMETERS FOR THE AVERAGE STRESS VERSUS STRETCH PLOTS OF COMPOSITE COMPOSITIONS IN FIGURE 8

\begin{tabular}{|cccccc|}
\hline Test Specimens & \multicolumn{3}{c}{ Yeoh } & \multicolumn{2}{c|}{ Humphrey } \\
\cline { 2 - 6 } & $\mathbf{c}_{\mathbf{1}}$ & $\mathbf{c}_{\mathbf{2}}$ & $\mathbf{c}_{\mathbf{3}}$ & $\mathbf{c}_{\mathbf{1}}$ & $\mathbf{c}_{\mathbf{2}}$ \\
\hline Test 1, FWF=0.58 & 0.0030 & 0.0010 & 0.0006 & 3.6 & 0.66 \\
Test 2, FWF=0.41 & 0.0022 & 0.0007 & 0.0003 & 1.9 & 0.42 \\
Test 3, FWF=0.47 & 0.0027 & 0.0008 & 0.0005 & 2.7 & 0.54 \\
Test 4, FWF=0.66 & 0.0039 & 0.0013 & 0.0008 & 4.3 & 0.75 \\
Test 5, FWF=0.87 & 0.0053 & 0.0020 & 0.0011 & 5.1 & 0.92 \\
Test 6, FWF=0.76 & 0.0047 & 0.0018 & 0.0010 & 4.9 & 0.89 \\
Test 7, FWF=0.71 & 0.0045 & 0.0017 & 0.0009 & 4.7 & 0.85 \\
Test 8, FWF=0.68 & 0.0039 & 0.0015 & 0.0008 & 4.5 & 0.78 \\
Test 9, FWF=0.64 & 0.0038 & 0.0013 & 0.0007 & 4.2 & 0.73 \\
Test 10, FWF=0.34 & 0.0016 & 0.0005 & 0.0001 & 0.8 & 0.15 \\
\hline
\end{tabular}

\section{CONCLUSIONS}

A novel conductive synthetic skin composite was developed using a multi-part silicone material embedded with short carbon fibers. Multiple test coupons were fabricated and tested for conduction to select an optimal fiber length $(5 \pm 0.5 \mathrm{~mm})$ for consistent conductivity. With the optimal fiber length, the effect of fiber weight fraction (FWF) on the conductivity of the composite material in unstretched state was investigated in detail. Also, mechanical tests were conducted to stretch the specimens to $100 \%$ and $200 \%$ elongations, and the consequent changes in conductivities were characterized. Based on the study, FWF ranges which will be suitable for conduction in unstretched and different stretched conditions were identified. The changes in fiber alignments due to repeated fiber stretching within the matrix of the novel composite material were analyzed. The stress versus stretch responses of the composite variants with different FWF's were presented and hyperelastic constitutive material models were used to characterize the results with a high $\mathbf{R}^{\mathbf{2}}$ correlation index of over 0.96 . To date, such a conductive synthetic skin composite material has not been developed to the best of our knowledge, which would be indispensable for mechanical testing, study of tissue mechanics and development of high fidelity surrogates for application in wearable technologies.

\section{ACKNOWLEDGEMENT}

VU would like to acknowledge the faculty start-up funds from The University of Alabama (UA), and the partial support of the NASA EPSCoR 2016 SID grants. Also, $\mathrm{AC}$ and VU would like to acknowledge the Optical Analysis Facility at UA for the microscopic imaging. 


\section{REFERENCES}

1. McGrath, J. and J. Uitto, Anatomy and organization of human skin. Rook's Textbook of Dermatology, Eighth Edition, 2010: p. 1-53.

2. Yannas, I. and J.F. Burke, Design of an artificial skin. I. Basic design principles. Journal of biomedical materials research, 1980. 14(1): p. 65-81.

3. Wang, Y., et al., Silicone-Based Tissue-Mimicking Phantom for Needle Insertion Simulation. Journal of Medical Devices, 2014. 8(2): p. 021001.

4. $\quad$ Payne, T., et al., Initial validation of a relaxed human soft tissue simulant for sports impact surrogates. Procedia engineering, 2014. 72: p. 533-538.

5. $\quad$ Payne, T., et al., The evaluation of new multi-material human soft tissue simulants for sports impact surrogates. Journal of the mechanical behavior of biomedical materials, 2015. 41: p. 336356.

6. Bir, C.A., M. Resslar, and S. Stewart, Skin penetration surrogate for the evaluation of less lethal kinetic energy munitions. Forensic science international, 2012. 220(1): p. 126-129.

7. Jussila, J., et al., Ballistic skin simulant. Forensic science international, 2005. 150(1): p. 63-71.

8. Amick, D., Gel compositions as muscle tissue simulant and related articles and methods. 2006, Google Patents.

9. Giurintano, D., et al., Torso simulator for ballistics testing. 2012, Google Patents.

10. Chanda, A. and H. Ghoneim, Pumping potential of a two-layer left-ventricle-like flexible-matrixcomposite structure. Composite Structures, 2015. 122: p. 570-575.

11. De Rossi, D., A. Della Santa, and A. Mazzoldi, Dressware: wearable hardware. Materials Science and Engineering: C, 1999. 7(1): p. 31-35.

12. Chanda, A. and V. Unnikrishnan. Human Tissue Simulants for Study of Traumatic Brain Injury (TBI). in Proceedings of the American Society for Composites: Thirty-First Technical Conference. 2016.

13. Chanda, A., V. Unnikrishnan, and Z. Flynn, Biofidelic skin simulant. 2016, Google Patents.

14. Gallagher, A., A. Ní Annaidh, and K. Bruyère. Dynamic tensile properties of human skin. in 2012 IRCOBI Conference Proceedings. 2012. International Research Council on the Biomechanics of Injury.

15. Annaidh, A.N., et al., Characterization of the anisotropic mechanical properties of excised human skin. Journal of the mechanical behavior of biomedical materials, 2012. 5(1): p. 139-148.

16. Martins, P., R. Natal Jorge, and A. Ferreira, A Comparative Study of Several Material Models for Prediction of Hyperelastic Properties: Application to Silicone-Rubber and Soft Tissues. Strain, 2006. 42(3): p. 135-147.

17. Chanda, A., et al., Biofidelic human brain tissue surrogates. Mechanics of Advanced Materials and Structures, 2016(just-accepted): p. 1-31.

18. Chanda, A., R. Graeter, and V. Unnikrishnan, Effect of blasts on subject-specific computational models of skin and bone sections at various locations on the human body. AIMS Mater Sci, 2015. 2(4): p. 425-447.

19. Chanda, A. and V. Unnikrishnan, A realistic 3D computational model of the closure of skin wound with interrupted sutures. Journal of Mechanics in Medicine and Biology, 2016: p. 1750025.

20. Chanda, A. and V. Unnikrishnan, Effect of Bladder and Rectal Loads on the Vaginal Canal and Levator Ani in Varying Pelvic Floor Conditions. Mechanics of Advanced Materials and Structures, 2017(just-accepted).

21. Chanda, A., et al., A biofidelic computational model of the female pelvic system to understand effect of bladder fill and progressive vaginal tissue stiffening due to prolapse on anterior vaginal wall. International journal for numerical methods in biomedical engineering, 2016.

22. Chanda, A., et al. Computational Modeling of Anterior and Posterior Pelvic Organ Prolapse (POP). in ASME 2016 International Mechanical Engineering Congress and Exposition. 2016. American Society of Mechanical Engineers.

23. Chanda, A., et al., Computational Modeling of the Female Pelvic Support Structures and Organs to Understand the Mechanism of Pelvic Organ Prolapse: A Review. Applied Mechanics Reviews, 2015. 67(4): p. 040801. 
24. Gonzalez, L.Y.S., M.G. Botero, and M. Betancur, Hyperelastic Material Modeling. 2005, Universidad EAFIT: Medell'in, Colombia, .

25. Holzapfel, G.A., Nonlinear solid mechanics. Vol. 24. 2000: Wiley Chichester. 